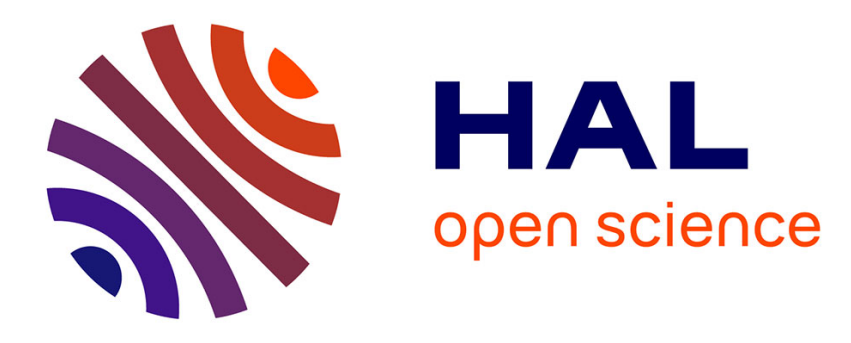

\title{
Rate Dependent Impact Fracture Toughness Analysis for Brittle Materials
}

K. Takahashi, G. Aggag, T. Mada

\section{To cite this version:}

K. Takahashi, G. Aggag, T. Mada. Rate Dependent Impact Fracture Toughness Analysis for Brittle Materials. Journal de Physique IV Proceedings, 1997, 07 (C3), pp.C3-1033-C3-1038. 10.1051/jp4:19973174 . jpa-00255469

\section{HAL Id: jpa-00255469 https://hal.science/jpa-00255469}

Submitted on 1 Jan 1997

HAL is a multi-disciplinary open access archive for the deposit and dissemination of scientific research documents, whether they are published or not. The documents may come from teaching and research institutions in France or abroad, or from public or private research centers.
L'archive ouverte pluridisciplinaire HAL, est destinée au dépôt et à la diffusion de documents scientifiques de niveau recherche, publiés ou non, émanant des établissements d'enseignement et de recherche français ou étrangers, des laboratoires publics ou privés. 


\title{
Rate Dependent Impact Fracture Toughness Analysis for Brittle Materials
}

\author{
K. Takahashi, G. Aggag and T. Mada \\ Research Institute for Applied Mechanics, Kyushu University, Kasugakoen, Kasuga 816, Japan
}

\begin{abstract}
Dependence of dynamic fracture toughness of brittle materials on impact velocity was studied for Charpy specimens using an instrumented measuring system. The measuring system includes not only a conventional dart gauge system but also a crack tip gauge system and an optical fiber system for measurement of dynamic displacement during impact. Brittle fracture of notched polycarbonate specimens was studied. A quasi-dynamic calibration method was adopted to determine the dynamic specimen compliance for evaluation of dynamic fracture toughness. The specimens had two types of notches; a V-shaped notch $(0.25 \mathrm{~mm}$ in lip radius) and a sharp razor notch. It has been shown from the results that, first, values of $K_{I C}$ or $G_{I C}$ evaluated directly from the impact dart gauge lead to an erroneous conclusion on the velocity dependence. Second, the toughness of PC-specimens decreases with the increase of the impact velocity from 1 to $5.5 \mathrm{~m} / \mathrm{sec}$. Third, a good agreement is obtained between values of the toughnesses evaluated from the optical method and those from the crack tip gauge. Fourth, Charpy specimens with blunt notches gave values of fracture energy which were three to four times higher than those obtained from sharp notched specimens. The effect of the impact velocity on the morphology of the fracture surface is discussed.
\end{abstract}

Résumé. La dépendance de la résistance à la fracture dynamique des materiaux fragiles proportionelle à la vitesse d' impact a été étudié avec des éprouvettes de type Charpy utilisant un système instrumentale. Le système comporte non-seulement des jauges à flèche mais aussi des jauges pour fissure ainsi qu'un système à fibre optique servant à mesurer le déplacement dynamique intervenat au moment de l'impact. La ruplure des éprouvettes en polycarbonate préentaillés a été étudié. La réponse dynamique de ces éprouvettes a été déterminé utilisant une méthode quasi-đynamique. Deux types d'entailles on été réalisé: une fente en forme de $V(0.25 \mathrm{~mm}$ de diamètre) et une fente directe. Les résultats oblenus démontrent que des conclusions erronées peuvent être obtenues pour les valeurs de $K_{i c}$ ou $G_{l C}$ quand à la dépendance de la vitesse d'impact lorsque celles-ci sont mesurées directement avec la jauge à impact à flèche. De plus, la résistance des éprouvettes décroit avec l'augmentation de la vitesse d'impact de 1 à $5,5 \mathrm{~m} / \mathrm{sec}$. Une bonne similarité entre les valeurs de la résistance évaluées avec la méthode optique et celles mesurées avec les jauges à frssure a été obtenue. Enfin, les échantillons comportant des entailles rugueuses donnent des valeurs d'énergie de fracture de 3 à 4 fois plus élevées que celles obtenues avec les échantillons à entailles directes et polies. L'effect de la vitesse d'impact sur la morphologie des fissures en surface est également discutée.

\section{INTRODUCTION}

Dynamic fracture toughness of polymeric materials has been widely studied through instrumented impact measurements [1-6]. Dependence of dynamic fracture toughness on loading rate has its appeal to researchers due to practical as well as academic importance of the problem. However, the impact tests are not free from technical problems arising from dynamic effects at higher loading rates. In impact tests with relatively slow loading rates on elastic materials, the load displacement diagram exhibits negligibly small oscillation and the fracture toughness values can be evaluated from the load displacement curve. However, at higher loading rates the signal from an impact dart contains oscillation signals caused by inertial and wave propagation effects in the impacting system [1-3], which should sometimes mislead the conclusion on the impact velocity dependency of dynamic fracture toughness.

Dynamic fracture toughness of PC has been studied by several investigators [6-9]. Adams et al. [6] studied the fracture initiation toughness using a conventional falling weight tester and analyzed obtained data on a basis of a spring mass model [7]. He showed a decreasing trend of the fracture toughness as a function of impact velocity up to $3 \mathrm{~m} / \mathrm{sec}$. Beguelin and Kausch [8] studied fracture initiation in polycarbonate compact tension specimens on a high speed tensile machine and showed that the initiation fracture energy does not decrease up to a loading velocity of $10 \mathrm{~m} / \mathrm{sec}$. Selden [9] determined the fracture energy of PC with different thicknesses at a lower strain rate up to $100 \mathrm{~mm} / \mathrm{min}$ under three point bending. He showed that fracture energy of a blunt notched specimen is by two to six times higher than that obtained from a sharp 
notched specimen. Also, he found the fracture toughness values slightly decreased with increasing strain rate from $0.1 \mathrm{~mm} / \mathrm{min}$ to $100 \mathrm{~mm} / \mathrm{min}$ with a sharp notch.

In the present study, dynamic fracture toughness of PC was evaluated on an instrumented impact tester of a falling weight type as a function of the impact speed up to $5.5 \mathrm{~m} / \mathrm{s}$. The effect of notch tip geometry was also studied. The results are correlated with fractographic observation made by an optical microscope.

\section{EXPERIMENTAL}

\subsection{Testing apparatus}

The testing system includes a falling dart $(2.6 \mathrm{~kg})$, various measuring equipment inclusive of an optical fiber system. Three kinds of signal sources are used in the system; a dart gauge, a crack tip gauge and a PSD sensor. A comparison between signals from the dart and the crack tip gauges is discussed in detail in [2]. The optical device employing the PSD sensor was originally developed by $\mathrm{Ph}$. Beguelin [10]. This method was adopted to evaluate the dynamic specimen deflection during impact. The device was composed of an optical fiber mounted on an upper surface of a specimen (see Fig. 1) and a position sensing device (PSD) which measured dynamic specimen bend displacement at the fiber position. The frequency response of the optical system has been proved to be wide $(-100 \mathrm{kHz})$ enough [11] for the present dynamic measurement. The PSD circuit did not employ electric filtering. On the other hand, the dart gauge signals were filtered by a $3 \mathrm{kHz}$ low-pass filtering circuit in the strain amplifier [12]. Output of the crack tip gauge were not filtered.

\subsection{Specimen preparation}

Polycarbonate Charpy specimens, whose dimensions are $15 \mathrm{~mm}$ in height and $10 \mathrm{~mm}$ in thickness, were prepared with two types of notches; a V-shaped notch $(0.25 \mathrm{~mm}$ in tip radius) and a sharp razor notch. The razor notching was done by drawing a razor blade along the root of the saw cut notch. The molecular weight $\left(W_{m}\right)$ of the specimen material was 36,300 . The crack tip gauge signal was employed to examine the fidelity of the optical fiber technique. Five specimens were tested for one experimental condition and an average value was obtained for each test.

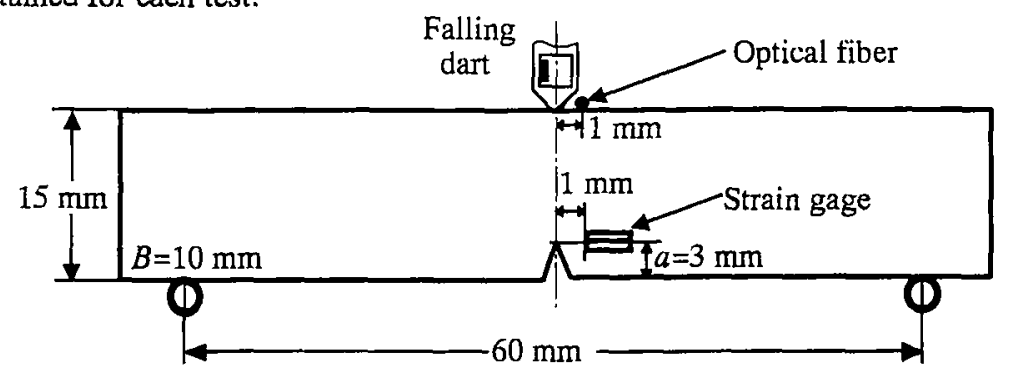

Figure I Specimen geometries, Crack tip gauge and optical fiber positions

\subsection{Determination of dynamic stress intensity factor $K_{I C}$ - quasi-dynamic calibration procedure}

Determination of the dynamic stress intensity factor, $K_{l C}$, was carried out in an impact velocity range from 1 to $5.5 \mathrm{~m} / \mathrm{s}$. The dart gauge signal was converted to load $F_{d}$ on the basis of a conventional static calibration method. On the other hand, values of specimen deflection $\delta_{s}$ was converted into values of load $F_{s}$ using a compliance method as follows. A quasi-dynamic calibration method was employed to determine the dynamic specimen compliance: At an impact velocity of $V_{i}=1 \mathrm{~m} / \mathrm{sec}$, where the dart signal was almost free from the dynamic impact effects and was almost linear with time up to fracture initiation [4], the specimen compliance $C_{s}$ was detemined by:

$$
C_{s}=\frac{\delta_{s}}{F_{d}} \quad\left(V_{i}=1 \mathrm{~m} / \mathrm{sec}\right)
$$


This value of compliance $C_{s}$ was then used to convert the specimen deflection to the load $F_{s}$ at higher velocities, i. e., $2.8,4.0$ and $5.5 \mathrm{~m} / \mathrm{sec}$ on the assumption that $C_{s}$ was almost unchanged at these velocities. Similar quasi-dynamic calibration method was used to determine the calibration factor of the crack tip gauge: Signals at $V=1 \mathrm{~m} / \mathrm{sec}$ from the dart gauge and from the crack tip gauge were utilized to determine the crack tip gauge calibration factor. Using this calibration factor the output of the crack tip gauge at higher impact velocities was also converted into load values $F_{a t}$. It is considered that $F_{s}=F_{a t}$. Values of $F_{s}$, i.e, $F_{a}$ were used to check appropriateness of $F_{d}$.

The critical dynamic stress intensity factor $K_{I C}$ was given by the following equation:

$$
K_{I C}=\frac{3}{2} \frac{s}{B W^{2}} \sqrt{a} Y\left(\frac{a}{W}\right) F_{\max }
$$

where $S, B, W, a$ and $Y(a / W)$ are span, specimen thickness, specimen width, notch length and the geometrical correction factor, respectively.

The energy per unit area at fracture initiation $G_{I C}$ was given by the LEFM formula [7]

$$
G_{I C}=\frac{U_{C}}{B W \phi}
$$

where $U_{C}$ is the stored elastic strain energy in the specimen at a point of crack initiation and $\phi$ is the energy calibration factor defined by $\phi=\frac{C}{d C / d(a / W)}$. The $U_{C}$ was obtained from the integration of the load versus displacement curve.

\section{RESULTS AND DISCUSSION}

\subsection{Signals from dart gauge, crack tip gauge and PSD}

Figure 2(a) exemplifies curves of the dart load $\left(F_{d}\right)$, specimen deflection versus time for a V-notched Charpy specimen. They were obtained at an impact velocity of $1.0 \mathrm{~m} / \mathrm{s}$ from the dart gauge and PSD, respectively. The load-time curve exhibits oscillation slightly as a consequence of the impact. In contrast, the deflection versus time curve remains almost quasi-linear. The time difference between the starting points of the two signals $(-20 \mu \mathrm{s})$ was caused by a delay which corresponded to a time needed for waves to propagate from the dart top to the gauge position of the dart. This delay time is negligible compared with the total fracture time $(1.9 \mathrm{msec})$. As shown in the Figure, the fracture initiation point could be detected clearly by the rapid change of the deflection curve. The detected crack initiation time was ca. $30 \mu$ s earlier than the initiation time determined by the dart signal at an instance of load drop initiation. The fiber system was sensitive enough to detect the crack initiation in this case. Figure 2(b) shows comparison of load and deflection curves obtained
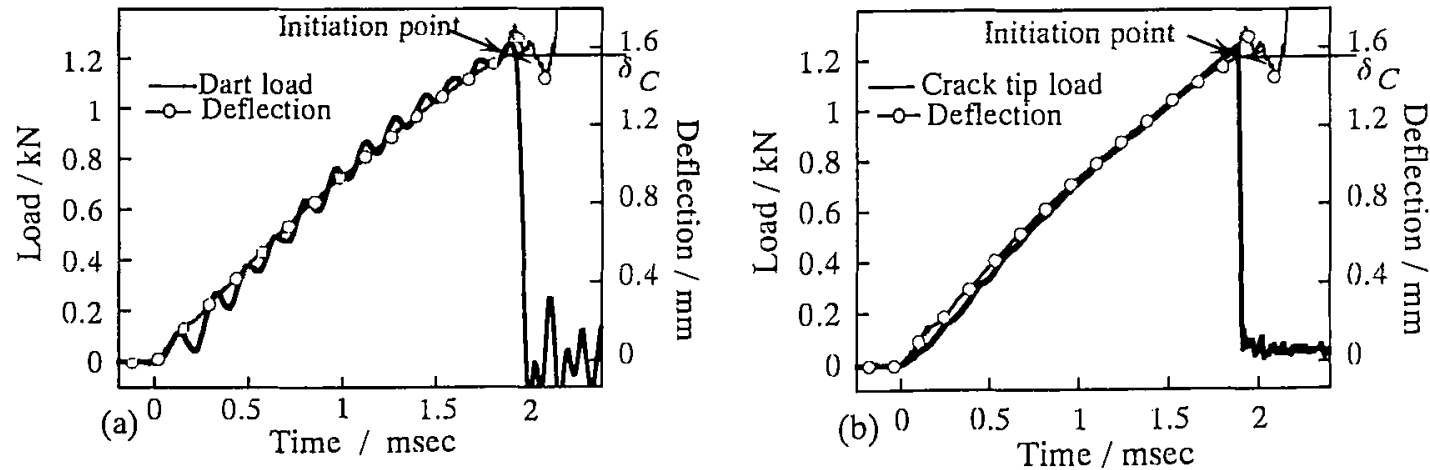

Figure 2 Dart load (a), crack tip load (b) and deflection curves versus time for $V$-notched PC-specimen $(1 \mathrm{~m} / \mathrm{sec})$ 
from the crack tip gauge and PSD sensor, respectively. The curve of the crack tip gauge is also quasi-linear similar to that of PSD. The agreement between crack initiation times indicated by the two curves is fairly good.

The dart gauge signals (upper) are compared in Fig. 3 with the crack tip gauge signals (middle) and PSD signals (bottom) at different impact velocities. They all show that with the increase of the impact velocity the time to fracture decreases. It is noted that the maximum load of the dart signal tended to increase in height almost proportionally with the impact velocity. This situation was similar with the first, so-called inertial, peak. Figure 3(b) indicates clearly when fracture were initiated and that the first peak in Fig. 3(a) is indifferent to the crack initiation. When the impact velocity was increased, it was not always easy to detect the crack initiation from the PSD output (see Fig. 3(c)). However, by comparison with the crack tip gauge output, the initiation could be precisely determined with the PSD signals as indicated by an arrow mark. In contrast to the increasing tendency of the peak of signals from the dart, these from the crack tip gauge and PSD sensor exhibited decrease in amplitude of the signals at crack initiation with the increase of the impact velocity. Thus, the results of Fig. 3 indicate that, when the impact velocity becomes higher, the reliability becomes less in the fracture toughness determination with the dart gauge.
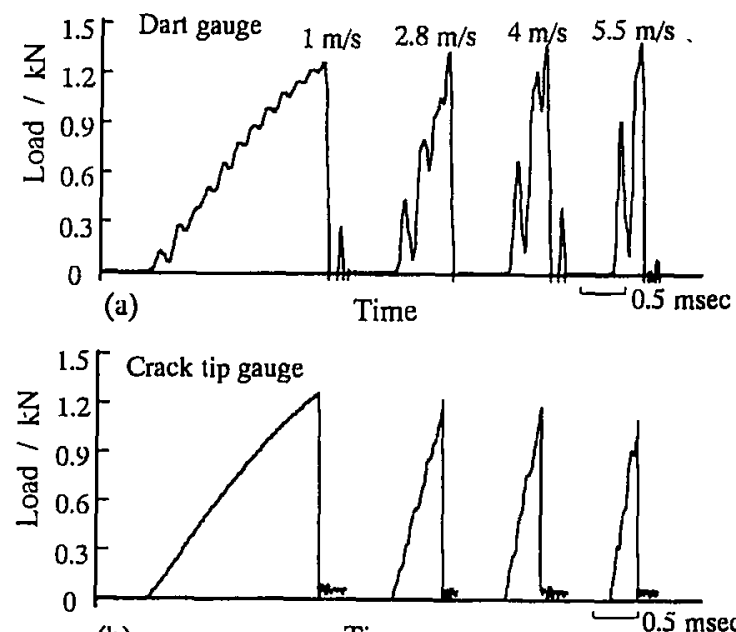

(b)

Time

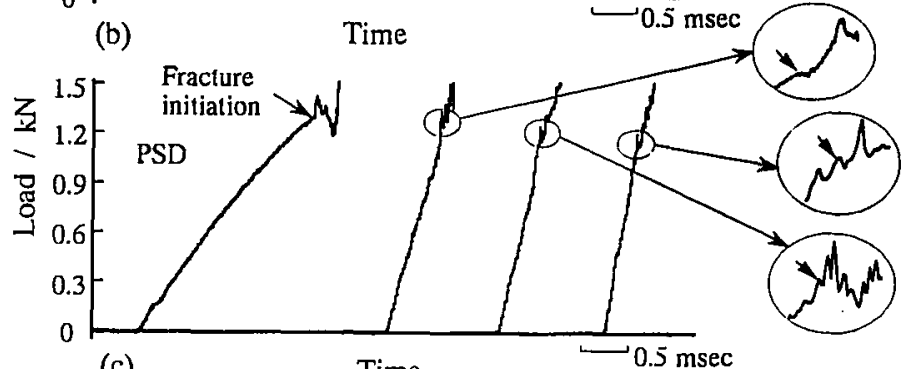

(c)

Time

Figure 3 Dart gauge signals in comparison with the crack tip and optical device signais for V-notched PC-specimen impacted at different velocities.

\subsection{Effect of impact velocity on $K_{I C}$ and $G_{I C}$}

Figures 4 (a) and (b) represent the effect of the impact velocity on the fracture toughness $\left(K_{I C}\right)$ and fracture energy $\left(G_{I C}\right)$ for PC specimens with a V-notch. Values evaluated by the three kinds of methods are presented. As indicated above, values of $K_{J C}$ evaluated by the dart gauge output showed an increase with increasing impact velocity. Instead, the crack tip gauge indicated that the toughness virtually decreased with the impact velocity. The analysis using the optical fiber method showed a good agreement with the crack tip gauge method. Plots of $G_{i C}$ values are shown in Fig. 4 (b). Again, data from the crack tip gauge and PSD showed a similar trend to that of $K_{I C}$ when the impact velocity increased. 

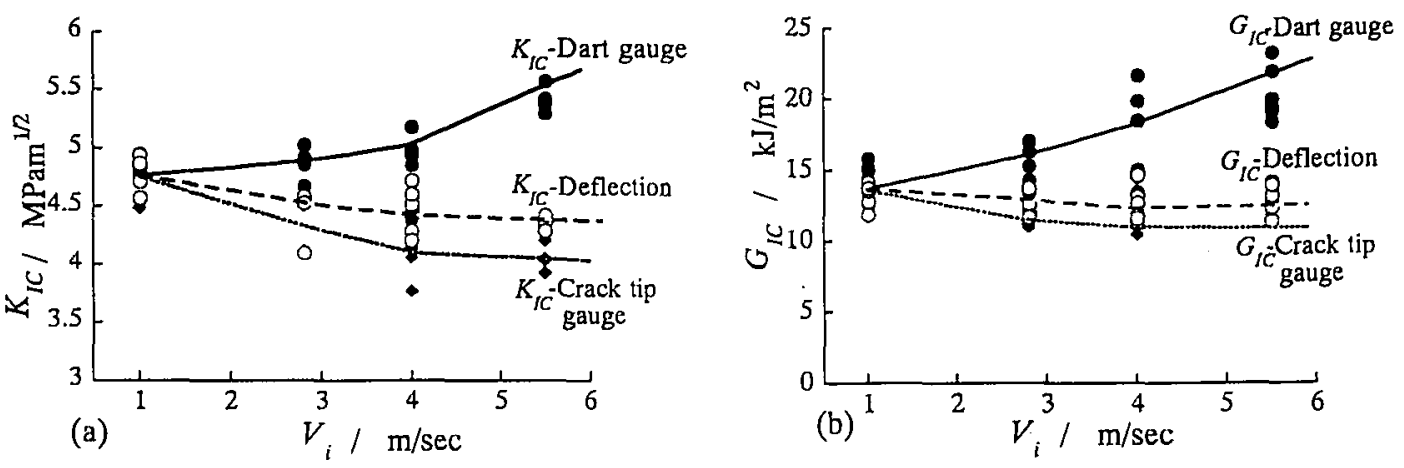

Figure 4 Curves representing relations $K_{I C}(\mathrm{a})$ and $G_{I C}$ (b) versus impact velocity for V-notched specimens

Figures 5(a) and (b) show the effect of razor notching on $K_{I C}$ and $G_{I C}$. The effect was evident with the values themselves. For $K_{I C}$, values were roughly one half of those of Fig. 4 (a), for $G_{I C}$, they were ca. one fifth. Another point to be noted is that except for values of $G_{I C}$-dart gauge, the dependency on $V_{i}$ was almost similar to that of $V$-notched specimens. The $G_{1 C}$ determined by the dart gauge did not exhibit marked tendency to increase with $V_{i}$. It is emphasized that proper fracture toughness values can be obtained only if sufficiently sharp notches are introduced. As for the velocity dependency, it is concluded that values of $K_{I C}$
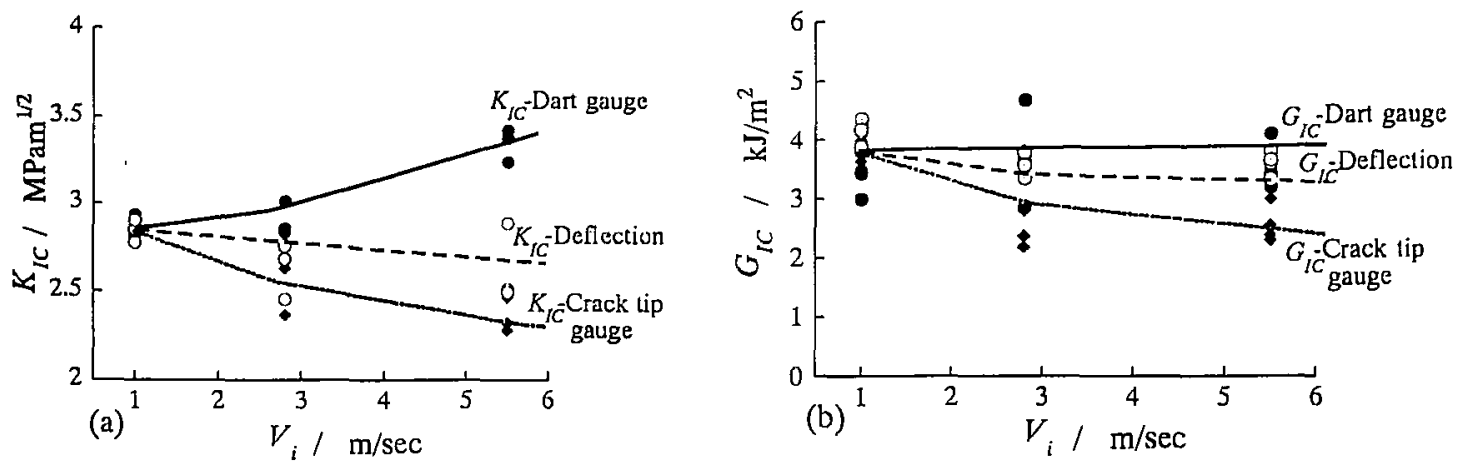

Figure 5 Curves to represent $K_{I C}$ (a) and $G_{I C}$ (b) versus impact velocity for razor-notched specimens

and $G_{I C}$ obtained from the dart gauge signals are considered highly misleading. Similar conclusion has been obtained by Böhme [13] for modified PVC in his study of fracture toughness using dart signal and crack-tip signals.

\section{FRACTURE SURFACE OBSERVATION}

Fracture surface examination was performed to confirm the effects of impact speed and notching on fracture surface topography. Figures 6 (a) and (b) show fracture morphology, near notch tip of razor-notched specimens tested at an impact velocity of 1 and $5.5 \mathrm{~m} / \mathrm{sec}$, respectively. Regional formation of a rougher zone surrounded by a smooth area is noted. The comparison of fracture surfaces yields the following points: The roughness on the fracture surface tended to decrease as $V_{i}$ increased. This observation are in a good agreement with the result of the rate dependency of $K_{I C}$ and $G_{I C}$ shown in Figure 5.

\section{CONCLUSIONS}

The following conclusions are obtained from the rate dependent impact brittle fracture tests for PC Charpy 


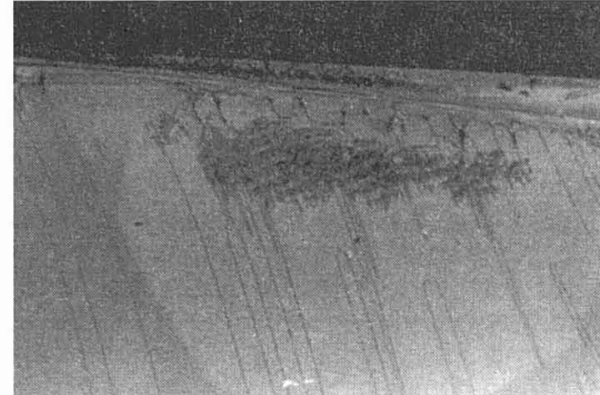

(a)

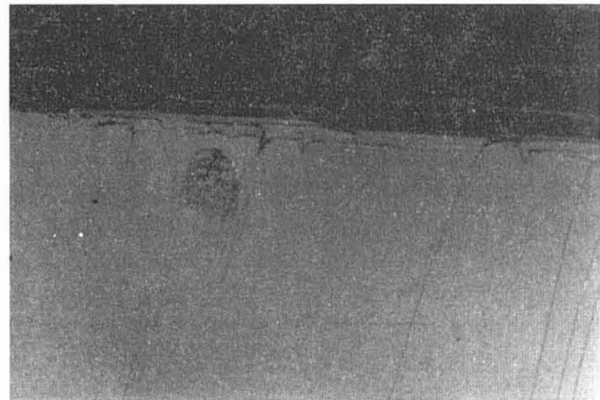

(b)

Figure 6 Micrographs of fractured surfaces of razor-notched PC-specimens lested at (a) $V_{i}=1 \mathrm{~m} / \mathrm{sec}$ and (b) $V_{i}=5.5 \mathrm{~m} / \mathrm{sec}$

specimens in an impact velocity $\left(V_{i}\right)$ range 1.0 to $5.5 \mathrm{~m} / \mathrm{sec}$ :

1. Increasing trend of $K_{I C}$ and $G_{I C}$ with $V_{i}$ obtained by dart gauge signals is erroneous.

2. The fracture toughnesses decrease with the increase of the impact velocity.

3. V-notched specimens give values of the fracture toughness which are ca. five times higher than those of razor-notched specimens.

4. Dynamic deflection of impacted Charpy specimens was evaluated using an optical fiber technique and fracture initiation could be detected by a sudden change in the deflection-time curve.

5. Using a quasi-dynamic compliance calibration method, values of the fracture toughness evaluated by specimen deflection was shown to agree well with those evaluated by the crack tip strain gauge.

6. Correlation between fracture toughnesses and fracture surface topography has been shown.

\section{Acknowledgments}

This work was supported by Grant-in-Aid for International Scientific Research (Joint Research) No. 07044160. The authors are indebted to Dr. Beguelin and Professor Kausch for their help in constructing the PSD sensor system.

\section{References}

[1] J. G. Williams, L. M. Braga and H. J. MacGillivray, in Impact and Dynamic Fracture of Polymer and Composites, ESIS 19 (Edited by J. G. Williams and A. P. Pavan) 1995, Mechanical Engineering Publication, London, PP. 45-57.

[2] G. Aggag and K. Takahashi, Polymer Engineering Science, Vol. 30, No 17 (1996) PP. 2260-2266.

[3] W Böhme and J. F. Kalthaff, Journal De Physique, Colloque C5, Supplément au n ${ }^{\circ}$, Tome 46, août (1985), PP. C5-213.

[4] K. Takahashi and A. F. Yee (eds.), Impact Fracture of Polymers, Kyushu University Press (1992) PP. $1-500$.

[5] J. F. Kalthoff, S. Winkler, J. Beinert, International Journal of Fracture 13 (1977) PP. 528-531.

[6] G. C. Adams, R. G. Bender, B. A. Crouch and J. G. Williams, Polymer Engineering Science, Vol. 30 (1990) PP. 241-248.

[7] J. G. Williams, in Fracture Mechanics of Polymers (Ellis Harwood, Chichester) (1984), PP. 238.

[8] P. Beguelin and H. H. Kausch, PP. 3-19 in Ref. 1.

[9] R. Selden, Polymers Testing, 7 (1987) PP. 209-222.

[10] $\mathrm{Ph}$. Beguelin, Ph. D thesis, Lausanne Institute of Technology (1996).

[11] T. Mada, K. Takahashi, Ph. Beguelin, and G. Aggag, to appear in Bulletin of Japan Society for Mechanical Engineers.

[12] K. Satoh and K. Takahashi, PP. 496 in Ref. 4.

[13] W. Böhme, PP. $59-71$ in Ref. 1. 